\title{
Chromogranins can be measured in samples from cats and dogs
}

\author{
Mats Stridsberg ${ }^{1 *}$, Ann Pettersson², Ragnvi Hagman², Christoffer Westin² and Odd Höglund²
}

\begin{abstract}
Background: Methods for objective evaluation of stress in animals are important, but clinically difficult. An alternative method to study the sympathetic activity may be to investigate Chromogranin A (CGA), Chromogranin B (CGB) and Secretogranin II (SG2). The aim of this study was to investigate the cross-reactivity of CGA, CGB and SG2 between man, cat and dog and to explore possibilities to measure these proteins in samples from cats and dogs.

Results: Adrenal gland extracts from feline and canine species were measured by region-specific radioimmunoassays in different dilution steps to explore possible inter species cross reactivity. High cross reactivity was found for cats in the CGA17-38, CGA324-337, CGA361-372, CGB and SG2 assays. High cross reactivity was found for dogs in the CGA17-38, CGA361-372, CGB and SN assays. The method measuring the intact CGA was not useful for measurements in cats and dogs.

Conclusions: Region-specific assays measuring defined parts of CGA, CGB and SG2 can be used for measurements in samples from cats and dogs. These results are promising and will allow for further studies of these proteins as possible clinical biomarkers in cats and dogs.
\end{abstract}

Keywords: Chromogranin, Secretogranin, Canine, Feline, Human, Radioimmunoassay

\section{Background}

Methods for objective evaluation of stress in animals are important, but clinically difficult. An alternative method to study the sympathetic activity may be to investigate Chromogranin A (CGA). CGA is part of a family of acidic and water soluble proteins called Granins, which also include Chromogranin B (CGB) and Secretogranins (SG) IIVII [1]. The Granins are stored in secretory granules of neuroendocrine tissues (chromaffin cells) and are released together with noradrenalin and adrenalin. Especially CGA is considered a reliable indicator of activation of the sympathetic tone [1,2]. Clinically, CGA and CGB are used for diagnosis and follow-up of various endocrine tumours [1]. CGA has also been proposed for evaluation of stress in intensive care units and for assessment of cardiovascular risk [3]. In critically ill patients an increased concentration of CGA is associated with shorter survival [4-8]. There are considerable differences in the amino acid composition between different animals and commercial assays for

\footnotetext{
* Correspondence: Mats.Stridsberg@medsci.uu.se

'Department of Medical Sciences, Uppsala University, SE-751 85 Uppsala, Sweden

Full list of author information is available at the end of the article
}

measuring human CGA can usually not be used for measuring CGA in samples from other species. However, some specific parts of the molecule have a higher degree of amino acid homology and methods where the antibodies are directed against specific epitopes can be used to measure samples from different animals [9].

The aim of this study was to investigate the crossreactivity of CGA, CGB and SG2 between man, cat and dog and to explore possibilities to measure these proteins in samples from cats and dogs.

\section{Methods}

Collection of adrenals and extraction of Chromogranins Adrenals were removed from a feline (Domestic short hair) and canine (German shepherd) specimen euthanized for reasons not associated with this study. The adrenals were weighed, frozen and lyophilized. The lyophilized material was homogenized in distilled water and boiled for $5 \mathrm{~min}$. The mixture was centrifuged at $10000 \mathrm{~g}$ for $15 \mathrm{~min}$ and the resulting supernatant was frozen in aliquots until measurements. 


\section{Measurements of Chromogranins in adrenal extracts}

Aliquots of supernatant derived from extracted adrenals were serial diluted in assay buffer and measured in the respective Granin assays. All assays were competitive radioimmunoassays, measuring defined parts of the Granin molecules. In this setting 5 region-specific assays were tested for determination of feline and canine CGA (CGA17-38, CGA176-195, CGA238-247, CGA324-337 and CGA361372) [10]. The extracts were also tested in an assay measuring Secretoneurin (SN), which is a defined part of SG2 [11], and in two commercial radioimmunoassays measuring human CGA and CGB (Eurodiagnostica AB, Malmö Sweden). All assays had a total assay variation of $<9 \%$.

\section{Amino acid sequences for Chromogranins}

Amino acid sequences for CGA (Accession numbers AAB53685. XP_006933167, XP_005623224), CGB (Accession numbers NP_001810, XP_006930003, XP_005634865) and SG2 (Accession numbers AAA36607, ABD24220, XP_545669) for human, feline and canine respectively, were obtained from the NCBI Protein data base.

\section{Statistics}

Measured values were expressed as mean values, standard deviation and coefficient of variation $(\mathrm{CV}) \%(=\% \mathrm{SD} / \mathrm{MV})$.

\section{Results}

The results from the measurements of CGA, CGB and $\mathrm{SN}$ in the adrenal extracts from cats are shown in Table 1 and the results from the measurements in dogs are shown in Table 2. Different concentrations were obtained with the different region-specific assays for CGA and the other assays. Low $\mathrm{CV}$ indicates reproducible measurements in different dilutions, which is a reliable indicator of high cross-reactivity. High $\mathrm{CV}$, on the other hand, indicates deviating results as signs of low crossreactivity and these concentration results cannot be considered as true estimates. Since the total assay variation in all assays were $<9 \%$, a $\mathrm{CV}$ of $<13.5 \%(=1.5 \mathrm{xCV})$ was used as the criterion to accept an assay as suitable for measurements in the feline or canine species. Low $\mathrm{CV}$ was found for cats in the CGA17-38, the CGA324-337, CGA361-372, the CGB and the SN assays. Low CV was found for dogs in the CGA17-38, the CGA361-372, the CGB and the SN assays. The method measuring the whole intact CGA was not useful for measurements in cats and dogs.

The amino acid sequence homology between human and feline was highest for CGA17-38 (100\%). Likewise, the homology was high, $100 \%$, for $\mathrm{SN}$, whereas the other assays had about $50-90 \%$ amino acid homology (Table 1). The amino acid sequence homology between human and canine was highest for CGA17-38 (100\%) and the homology was high, $100 \%$, also for SN, whereas the other assays had about 70-80\% amino acid homology (Table 2).

\section{Discussion}

The aim of this study was to investigate the crossreactivity of CGA between man, cat and dog and to explore possibilities to measure CGA in samples from cats and dogs. Since plasma samples with high concentrations of CGA are difficult to find in animals, we choose to use extracts of Chromogranins from adrenal glands, an organ known to contain high concentrations of CGA, CGB and SG2 [12]. Using the supernatant from adrenal extracts, we were able to obtain high enough concentrations to allow serial dilution, which is an established way to explore cross reactivity. Similar experiments have been performed earlier for bovine, equine, ovine and caprine species [9]. In agreement with our results, as in the previous study [9], the CGA17-38 assay showed cross reactivity between the species, while the CGA assay measuring the whole intact CGA molecule, which corresponds to the Eurodiagnostica assay used in this study, was not useful. Interestingly, some assays with lower amino acid homology showed cross reactivity, while others did not. It is known that, in particular, charged amino acids are highly immunoreactive. An exchange between species of one or more of these crucial amino acids will give a high impact on the antibody

Table 1 Assays used for the cross reactivity studies in adrenal extracts from cat

\begin{tabular}{|c|c|c|c|c|c|}
\hline Assay & MV & SD & CV & Suitable assay & Aa homology \\
\hline CGA 17-38 & 3,26 & 0,16 & $4,8 \%$ & Yes & $100 \%$ \\
\hline CGA 176-195 & 0,14 & 0,02 & $16,7 \%$ & No & $59 \%$ \\
\hline CGA 238-247 & 0,23 & 0,08 & $35,4 \%$ & No & $90 \%$ \\
\hline CGA 324-337 & 3,04 & 0,88 & $29,0 \%$ & No & $93 \%$ \\
\hline CGA 361-372 & 1,16 & 0,04 & $3,4 \%$ & Yes & $83 \%$ \\
\hline SG2 154-165 & 3,79 & 0,10 & $2,7 \%$ & Yes & $100 \%$ \\
\hline CGB (Eurodiagnostica) & 2,31 & 0,30 & $12,8 \%$ & Yes & $85 \%$ \\
\hline CGA (Eurodiagnostica) & 14,63 & 3,23 & $22,1 \%$ & No & \\
\hline
\end{tabular}

The table shows the assays used for the cross reactivity studies of Chromogranin A (CGA), Chromogranin B (CGB) and Secretogranin II (SG2) measurements in adrenal extracts from cat. A coefficient of variation $(\mathrm{CV}=\mathrm{SD} / \mathrm{MV})$ less than $13.5 \%(=1.5 \mathrm{x}$ assay $\mathrm{CV})$ was considered acceptable for measurements i.e. determined as a suitable assay, see text for explanation. The amino acid $(\mathrm{Aa})$ homology between the human and feline species is indicated for the different assays. 
Table 2 Assays used for the cross reactivity studies in adrenal extracts from dog

\begin{tabular}{llllll}
\hline Assay & MV & SD & CV & Suitable assay & Aa homology \\
\hline CGA 17-38 & 3,02 & 0,26 & $8,8 \%$ & Yes & No \\
CGA 176-195 & 0,10 & 0,02 & $15,5 \%$ & No & $79 \%$ \\
CGA 238-247 & 0,24 & 0,11 & $47,0 \%$ & Yes & $75 \%$ \\
CGA 324-337 & 1,41 & 0,18 & $12,7 \%$ & Yes & $79 \%$ \\
CGA 361-372 & 0,46 & 0,02 & $3,6 \%$ & Yes & $100 \%$ \\
SG2 154-165 & 7,22 & 0,48 & $6,7 \%$ & Yes & $77 \%$ \\
CGB (Eurodiagnostica) & 3,89 & 0,42 & $10,7 \%$ & No & \\
CGA (Eurodiagnostica) & 4,99 & 1,22 & $24,5 \%$ & &
\end{tabular}

The table shows the assays used for the cross reactivity studies of Chromogranin A (CGA), Chromogranin B (CGB) and Secretogranin II (SG2) measurements in adrenal extracts from dog. A coefficient of variation ( $C V=S D / M V)$ less than $13.5 \%(=1.5 \times$ assay $C V)$ was considered acceptable for measurements i.e. determined as a suitable assay, see text for explanation. The amino acid (Aa) homology between the human and canine species is indicated for the different assays.

binding to the antigen. It is thus possible that such substitution has occurred for the CGA176-195 and CGA238247 parts of the molecule in cats and for the CGA176-1 95, CGA238-247 and CGA324-337 epitopes in dogs, thus explaining the poor cross reactivity although the apparent amino acid homology was rather high. Some CGA assays in the present study appear to be useful for measurements of Chromogranins in both cats and dogs. These assays measure known epitopes of CGA, which have been identified with biological activity (the CGA17-38 is also called Vasostatin and the CGA361-372 is also called Catestatin [13]). This is also the case with the part of SG2, i.e. SN, we have used in this study [11]. It is thus likely that peptides with biological activity have highly conserved inter-species amino acid homology and, as seen in this study, are useful for quantitative measurements.

All assays used in this study have previously been used for measurements of circulating concentrations of Chromogranins in plasma from human patients with neuroendocrine tumours [11,13]. However, Chromogranins have multiple sites that are likely to be cleaved both before and after release to the circulation. Accordingly different molecular forms of Chromogranins are likely to be found in the circulation. A more precise way to estimate the circulating concentrations of Chromogranins and other proteins, processing-independent assays, has been presented [14]. However, the use of region-specific assays with defined antibody epitopes, as in this study, can also be a way to assess the problem with different circulating molecular forms. It has also been shown that circulating concentrations of Chromogranins has a diurnal variation, a fact that should be considered in the planning of experiments [15].

CGA has been measured in plasma from cats and dogs with antibodies directed against both the C-terminal and the N-terminal of human CGA [16]. CGA has also been measured in plasma samples and adrenal extract from dogs $[17,18]$. Salivary concentrations have been measured in dogs [19]. This was done with an ELISA-kit from Yanaihara Institute, Japan, where the antibodies were directed against the epitope CGA344-374, which roughly covers the same region as one of the assays in this study, CGA361-372 (Catestatin).

\section{Conclusions}

In conclusion, we have identified parts of CGA, CGB and SG2 and assays that can be used for measurements of samples from cats and dogs. These results are promising and will allow for further studies of these proteins as possible clinical biomarkers for sympathetic activity and stressful situations in cats and dogs and possible even other diseases.

\section{Ethics}

Adrenals were removed from a feline and canine specimen euthanized for reasons not associated with this study. Tissue sampling was performed according to the ethical regulations in Sweden (Swedish Board of Agriculture, Dnr 38-9492/12) after written informed owner consent had been obtained.

\section{Abbreviations}

CGA: Chromogranin A; CGB: Chromogranin B; SG2: Secretogranin II; $\mathrm{SN}$ : Secretoneurin.

\section{Competing interests}

The authors declare that they have no competing interests.

\section{Authors' contributions}

MS planned the study, performed the laboratory work, performed the statistical analysis and drafted the manuscript. AP and RH participated in study design and coordination. CW conceived of the study and participated in study design. $\mathrm{OH}$ conceived of the study, participated in its design and coordination. All authors have participated in the preparation of the manuscript and approved the final manuscript.

\section{Acknowledgements}

This study supported by the Lions Cancer Foundation (MS), the Erik, Karin and Gösta Selanders fund (MS), the Amanda Personnes' Research Fund (OH), and Thure F. and Karin Forsberg's Reserach Foundation (RH).

\section{Author details}

'Department of Medical Sciences, Uppsala University, SE-751 85 Uppsala, Sweden. ${ }^{2}$ Department of Clinical Sciences, Swedish University of Agricultural Sciences, Box 7054, SE-750 07 Uppsala, Sweden. 


\section{References}

1. Taupenot L, Harper KL, O'Connor DT: The chromogranin-secretogranin family. N Engl J Med 2003, 348:1134-1149.

2. Cryer PE, Wortsman J, Shah SD, Nowak RM, Deftos LJ: Plasma chromogranin $\mathrm{A}$ as a marker of sympathochromaffin activity in humans. Am J Physiol 1991, 260:E243-E246.

3. d'Herbomez M, Do Cao C, Vezzosi D, Borzon-Chasot F, Baudin E: Chromogranin A assay in clinical practice. Ann Endocrinol (Paris) 2010, 71:274-280.

4. Zhang D, Lavaux T, Sapin R, Lavigne T, Castelain V, Aunis D, Metz-Boutigue $\mathrm{MH}$, Schneider F: Serum concentration of chromogranin $\mathrm{A}$ at admission: an early biomarker of severity in critically ill patients. Ann Med 2009, 41:38-44.

5. Zhang D, Lavaux T, Voegeli AC, Lavigne T, Castelain V, Meyer N, Sapin R, Aunis D, Metz-Boutigue MH, Schneider F: Prognostic value of chromogranin A at admission in critically ill patients: a cohort study in a medical intensive care unit. Clin Chem 2008, 54:1497-1503.

6. Røsjø H, Nygård S, Kaukonen KM, Karlsson S, Stridsberg M, Ruokonen E, Pettilä V, Omland T: Prognostic value of chromogranin A in severe sepsis: data from the FINNSEPSIS study. Intensive Care Med 2012, 38:820-829.

7. Røsjø H, Opstad PK, Hoff JE, Godang K, Christensen G, Stridsberg M, Omland T: Effect of short- and long-term physical activities on circulating granin protein levels. Regul Pept 2013, 185C:14-19.

8. Lindahl AE, Low A, Stridsberg M, Sjoberg F, Ekselius L, Gerdin B: Plasma chromogranin A after severe burn trauma. Neuropeptides 2013, 47:207-212

9. Stridsberg $\mathrm{M}$, Angeletti $\mathrm{RH}$, Helle KB: Characterisation of $\mathrm{N}$-terminal chromogranin $A$ and chromogranin $B$ in mammals by region-specific radioimmunoassays and chromatographic separation methods. J Endocrinol 2000, 165:703-714.

10. Stridsberg M, Eriksson B, Öberg K, Janson ET: A panel of 11 region-specific radioimmunoassays for measurements of human chromogranin $\mathrm{A}$. Regul Pept 2004, 117:219-227.

11. Stridsberg M, Eriksson B, Janson ET: Measurements of secretogranins II, III, $V$ and proconvertases $1 / 3$ and 2 in plasma from patients with neuroendocrine tumours. Regul Pept 2008, 148:95-98.

12. Hagn C, Schmid KW, Fischer-Colbrie R, Winkler H: Chromogranin A, B, and C in human adrenal medulla and endocrine tissues. Lab Invest 1986, 55:405-411.

13. Helle KB: Chromogranins A and B and secretogranin II as prohormones for regulatory peptides from the diffuse neuroendocrine system. Results Probl Cell Differ 2010, 50:21-44.

14. Goetze JP, Alehagen U, Flyvbjerg A, Rehfeld JF: Making sense of chromogranin A in heart disease. Lancet Diabetes Endocrinol 2013, 1:7-8

15. Takiyyuddin MA, Neumann HP, Cervenka JH, Kennedy B, Dinh TQ, Ziegler MG, Baron AD, O'Connor DT: Ultradian variations of chromogranin A in humans. Am J Physiol 1991, 261:R939-R944.

16. Myers NC 3rd, Andrews GA, Chard-Bergstrom C: Chromogranin A plasma concentration and expression in pancreatic islet cell tumors of dogs and cats. Am J Vet Res 1997, 58:615-620.

17. Akiyoshi H, Aoki M, Shimada T, Noda K, Kumagai D, Saleh N, Sugii S, Ohashi F: Measurement of plasma chromogranin A concentrations for assessment of stress responses in dogs with insulin-induced hypoglycemia. Am J Vet Res 2005, 66:1830-1835.

18. Akiyoshi H, Sugii S, Nahid MA, Sone K, Tanaka T, Zheng C, Yijyun L, Aoki M Takenaka S, Shimada T, Shimizu J, Kiyomiya K, Ohashi F: Detection of chromogranin A in the adrenal gland extracts of different animal species by an enzyme-linked immunosorbent assay using Thomsen-Friedenreich antigen-specific Amaranthus caudatus lectin. Vet Immunol Immunopathol 2011, 144:255-258

19. Kanai $K$, Hino M, Hori Y, Nakao R, Hoshi F, Itoh N, Higuchi S: Circadian variations in salivary chromogranin a concentrations during a 24-hour period in dogs. J Vet Sci 2008, 9:421-423.

\section{Submit your next manuscript to BioMed Central and take full advantage of:}

- Convenient online submission

- Thorough peer review

- No space constraints or color figure charges

- Immediate publication on acceptance

- Inclusion in PubMed, CAS, Scopus and Google Scholar

- Research which is freely available for redistribution 